\title{
Mining
}

http://dx.doi.org/10.1590/0370-44672016700071

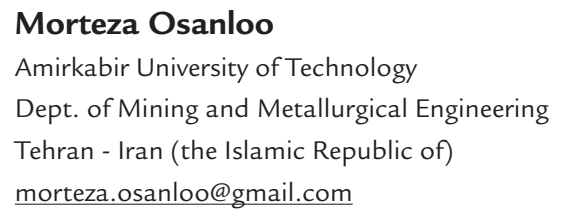

\section{Mehdi Rahmanpour}

Amirkabir University of Technology

Dept. of Mining and Metallurgical Engineering

Tehran - Iran (the Islamic Republic of)

rahmanpour@aut.ac.ir

\section{Optimizing short-term production plan using a portfolio optimization model}

\section{Abstract}

Short-term production plans are the basis for operational mine production schedules. They concentrate on making long-term mine plans operationally feasible. It ensures a steady flow of product for meeting blending targets. Due to the quality variation of material, blend optimization is an uncertainty based optimization problem. There are different approaches toward uncertainty management and the current paper investigates a portfolio optimization model in order to minimize the risks in short-term plans. In this paper, a fuzzy linear programming model is formulated to provide a set of options for the mine plan. These blending options are treated as portfolios. Then a model for the optimal selection of a portfolio is introduced. The objective of the model is to maximize the expected return of the portfolio under constraints limiting its variance. The model is applied in a limestone mine complex.

Keywords: short-term planning, portfolio optimization, fuzzy linear programming, uncertainty.

\section{Introduction}

The strategic mine plan sets the overall objectives of a mining project. Mine planning is a multidisciplinary act and its aim is to develop the yearly extraction plan to meet some predefined goals (Morley et al. 1999; Dagdelen 2007). Mine-plans are classified into long-term, medium, short-term, and operational plans. Normally, these plans are organized such that the mining operation leads to the highest cash flow or net present value (Juarez et al. 2014; King 2014). These plans should consider the constraints on capacities, blending, block sequencing, reclamation requirements, pit slope, and any constraints that may exist on each particular mine site (Caccetta and Hill 2003; Marques et al. 2013; Badiozamani and Askari-Nasab 2014). During the feasibility studies, the precise values of all the input parameters are not known. The normal practice is that, the input data such as geologic block model, grades, operating costs, commodity prices, recover- ies and the operational constraints are all estimated using the data available at the time of planning. It is obvious that, as planning parameter changes, the production plan should be reoptimized using updated data.

Uncertainty is defined as the difference between the amount of information required and the amount of available information to perform a task. The uncertainties are categorized into some environmental and system uncertainties (Mula et al. 2006). Environmental or external uncertainty includes uncertainties beyond the production, such as supply and demand uncertainty. System or internal uncertainty is related to those within the production process itself, such as operation yield uncertainty, quality uncertainty and failure of production system. In the case of mine planning, geologic, technological, market, political, and ecological factors are inherited with uncertainty. These uncertainties highlight the importance of a risk-based mine planning by using new production-planning models (Osanloo et al. 2008; Newman et al. 2010). For example, dynamic change of estimated ore and waste material due to spatial grade uncertainty challenges the finding of optimal mining plans (Godoy and Dimitrakopoulos 2004;Azimi et al. 2013).

The simplest approach to manage and overcome uncertainties is to overdesign or over-plan. In this approach, excess capacity of those specified in the long-term plan is executed, so that the operation can survive possible changes in the future. While this approach is expensive and it increases the inventory costs, it reduces possible breakdown costs in the future. This strategy reduces the production risk. However, the question is: how much the over-design could reduce the production risk? To answer this question, short-term planning is investigated as a portfolio optimization problem.

Short-term planning in open pit 
mines is studied by many researchers. Smith (1998) presented a Mixed Integer Linear Programming (MILP) model for the purpose of annual mine planning. Smith and Dimitrakopoulos (1999) considered grade uncertainty in short term planning based on MILP models. Kumral and Dowd (2002) combined simulated annealing and Lagrangian parameterization for short term planning in non-metallic mines.

\section{Constrained portfolio optimization}

Assume that there are $\mathrm{N}$ risky assets, each has an expected return $\mu_{i}$, and $\sigma_{i j}$ denotes the covariance of returns for assets $\mathrm{i}$ and $\mathrm{j}$. In a portfolio, expected return

The aim of Portfolio Optimization (PO) is to find the optimum way of investing a particular amount of money in these assets. In an optimum portfolio, the overall risk is minimized through diversification by investing in a variety of assets. For optimizing a portfolio,

Where, $\mathrm{E}\left(\mu_{p}\right)$ denotes the required level of expected return for the portfolio. Eq. (3) minimizes the variance (risk) associated with the portfolio while Eq. (4) ensures that the sum of assets' proportions in the portfolio is equal to one. Eq. (5) ensures that the portfolio has an expected return of $\mathrm{E}\left(\mu_{p}\right)$. Eq. (6) indicates that the proportion of each asset is at least zero. With respect to Eq. (4) and (6), the maximum proportion of each asset is at most one.

According to PO model, a feasible portfolio is the one that the sum of assets' proportions is equal to one. A portfolio that minimizes the risk for a given level of return is called an efficient portfolio. The set of all efficient portfolios is called
Fioroni et al. (2008) optimized monthly schedules in open pit mines using a combination of linear programming and simulation. Gholamnejad (2008) optimized mining sequence using a binary Integer Programming (BIP) model and he incorporated different sequencing options in the model. Souza et al. (2010) developed a hybrid heuristic algorithm for truck allocation in a multi pit iron-ore mine site to meet a recommended mining rate, while satisfying the quality requirements in order to minimize operating costs. Asad (2011) developed a heuristic approach for short-range production scheduling in a quarry. Eivazy and Askari-Nasab (2012) presented a model for short-term production scheduling (i.e. monthly plans), that aims to minimize mining costs while satisfying quality requirements. is the weighted average of the expected returns of all assets. Moreover, the risk of a portfolio depends on the weights and the correlations of assets. The weights

$$
\begin{gathered}
\mathrm{E}\left(\mu_{p}\right)=\sum_{i \in N} x_{i} \mu_{i} \\
\operatorname{Var}\left(\mu_{p}\right)=\sum_{i \in \mathcal{N}} \sum_{j \in N} x_{i} x_{j} \sigma_{i j}
\end{gathered}
$$

Markowitz (1952) presented the meanvariance model. In this model, it is assumed that the total return of a portfolio can be described using the mean and the variance (risk) of return of assets. The model is a convex quadratic programming problem with a polynomial worst-

$$
\begin{gathered}
\operatorname{Min} \operatorname{Var}\left(\mu_{p}\right)=\sum_{i \in N} \sum_{j \in N} x_{i} x_{j} \sigma_{i j} \\
\sum_{i \in N} x_{i}=1 \\
\sum_{i \in N} \mu_{i} x_{i}=\mathrm{E}\left(\mu_{p}\right) \\
x_{i} \geq 0, \forall i \in N
\end{gathered}
$$

efficient frontier or simply the efficient envelope (Benninga, 2008). The portfolios located above the envelope are not feasible portfolios (Fig. 1). It means that the sum of assets' proportions is not equal to one. The portfolios located on and below the envelope are feasible portfolios, and those that are located on the envelope are feasible and efficient portfolios. Let $\varphi\left(\mathrm{E}\left(\mu_{p}\right)\right)$ define the optimal value of the PO model as a function of $\mathrm{E}\left(\mu_{p}\right)$. Let $\mathrm{E}\left(\mu_{p}\right)_{\min }$ be the value of $\sum_{i=N} \mu_{i} x_{i}$ at an optimal solution where the constraint (5) is removed, and let $\mathrm{E}\left(\mu_{p}\right)_{\max }=\operatorname{MAX}\left\{\mu_{p}, \mu_{2}, \ldots, \mu_{n}\right\}$. Then $\varphi\left(\mathrm{E}\left(\mu_{p}\right)\right)$ on $\left[\mathrm{E}\left(\mu_{p}\right)_{\text {min }}, \mathrm{E}\left(\mu_{p}\right)_{\max }\right]$ interval represents the set of non-dominated portfolios (i.e. envelope). case complexity bound. It determines the proportion $x_{i}$ of a given capital to be invested in asset $i$, such that the risk of the portfolio's return is minimized. In addition, it restricts the expected return of the portfolio to a given value. The Markowitz' model is as follows:

are equal to the proportions of the assets in the portfolio $\left(x_{i}\right)$. Then, the portfolio's expected return $\left(E\left(\mu_{p}\right)\right)$ and variance $\left.\operatorname{Var}\left(\mu_{p}\right)\right)$ are calculated using Eq. (1)-(2).

According to Markowitz, investors could eliminate exposure to risks of individual stocks by choosing them such that they do not move the same way. In this respect, correlation coefficient measures the joint movements of two stocks. Riskaverse investors want portfolios with a small variance and high expected return. By adding some realistic constraint to the PO model, the constrained model is obtained. In the modified model, assume that $\mathrm{K}$ assets should be held in the portfolio. Furthermore, the portion $x_{i}$ that is included in the portfolio should be limited within a given lower and upper bounds $\left[I_{i}, u_{i}\right]$.These constraints are given in Eq. (7)-(9). 
Figure 1

Efficient frontier and

the different types of portfolios.

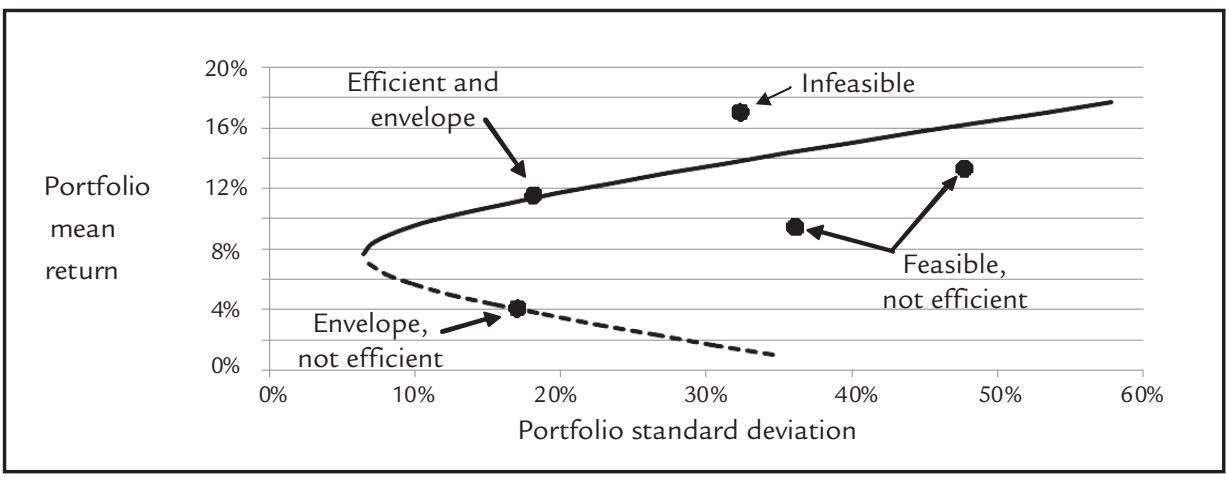

$$
\begin{gathered}
\sum_{i \in N} y_{i}=K \\
l_{i} y_{i} \leq x_{i} \leq u_{i} y_{i}, \forall i \in N \\
y_{i}=0 \text { or } 1, \forall i \in N
\end{gathered}
$$

form of portfolio optimization model (Fernandez and Gomez, 2007). This model is an integer quadratic programming model.

\section{PO application in mine planning}

This paper addresses short-term planning in open pit mines. Long-term plans dedicate the strategies to reach the company's goals (the highest net present value, for instance). However, short-term plans are aimed to follow the strategies of long-term plan and to minimize the operating costs as much as possible. In a mining operation, materials are mined from different blocks, faces and benches, and hauled to some predetermined destinations based on their properties. Run of mine quality depends on the quality and quantity of

the material mined from each face.

Material properties can vary considerably even in a mining face. During feasibility studies, parameters such as grades, operating costs, commodity prices, recoveries and the operational constraints are all estimated based on the data available at the time of planning. These estimations and their uncertainties affect the mine-plan in reaching its predefined goals. Due to fluctuations in price, costs, and mining recovery, each mining face can be considered as a risky asset. Then, ap- plication of $\mathrm{PO}$ is efficient in reducing the risk of mine plan. Diversification of mineral production in a mining operation will decrease the risks of not achieving the production goals. In financial applications of PO model, one could assume a possibility of short sale. In this case, $x_{i}$ will be changed into a free variable and Eq. (6) will be removed from the model. However, in mining applications, it is not logical to have a short sale. Thus, in this application, the model is solved by short sale restriction.

\section{Model development}

In a mining system, the aim of mine-planner is to determine the optimum amount of material that should be mined from each face such that the customer (or the processing plant) is provided with a suitable quantity and quality of raw material. Short-term plans follow the objectives of the strategic and long-term plans. Normally, the objective function of a short-term planning model is to minimize total mining costs by optimizing the amount of material that should be mined from each face.

Each mining face is considered as a risky asset. In that regard, by application of the model described in Eq. (3)-(5) and (7)-(9) the best configuration for the shortterm mining schedule is optimized. In this model, each mining face is configured by a mean return and a risk level. These two properties could be determined using the historical data in active mining faces. The other way to determine these properties is simulation. In this case, the mean return and a risk level of each mining face could be simulated using the available data at the time of planning. The PO model, given in Eq. (3)-(5) and (7)-(9), does not consider the operating constraints existing in the faces. The most important factors that affect the mining schedule, that are inherited with uncertainty are the in-situ quality of mineable reserve, the capacities, the mining costs, and commodity price. The mining and processing recoveries are functions of chemical, physical and mechanical properties of the material in each face. In order to embed these constraints to the model, a Fuzzy Linear Programming (FLP) model is developed (Eq. 10-16). The notions used in the model are as follows: $N$ is the set of mine sites, $c_{i}$ is the average operating cost in site $i, x_{i}$ is the decision variable and it determines the amount of material mined from site $i, r_{i}$ is the recovery of material in site $i, M_{C}$ is the minimum mining rate, $M_{i}$ is the maximum possible mining rate in site $i, P C$ is the feed rate required by the plant or the customer, $g_{i}$ is the average grade of useful mineral in site $i, q_{i, k}$ is the average grade of penalty element of impurity $k$ in site $i, G_{\min }$ is the minimum acceptable grade of useful mineral, $Q_{i \text { max }}$ is the maximum acceptable grade of impurity $k$, and $K$ is the number of impurities or the penalty elements in the mine complex.

Objective function: The objective function of the model is defined as minimization of the total mining costs in the system (Eq. 10-16). 


$$
\operatorname{Min} \sum_{i \in N} \tilde{c}_{i} x_{i}
$$

Capacity constraint: It ensures that the summation of the mined material is equal or greater than the amount

Quality constraint: Eq. (13) and (14) are the constraints required by the quality control. Eq. (13) ensures that the total amount of penalty elements in feed does not that total amount of final product produced

The symbol $\sim$ indicates fuzzy parameters in the model. These parameters are Bounded Fuzzy Numbers (BFN). The lower bound of BFN represents a risk-free

\section{Model verification}

The models (Eq. (3)-(5) and (7)(9), Eq. 10-16) are tested using the data gathered from a limestone mine complex in Iran. There are five distinct mining areas, in which the quantity and quality of the mineable limestone are different from one another. In these mines, the
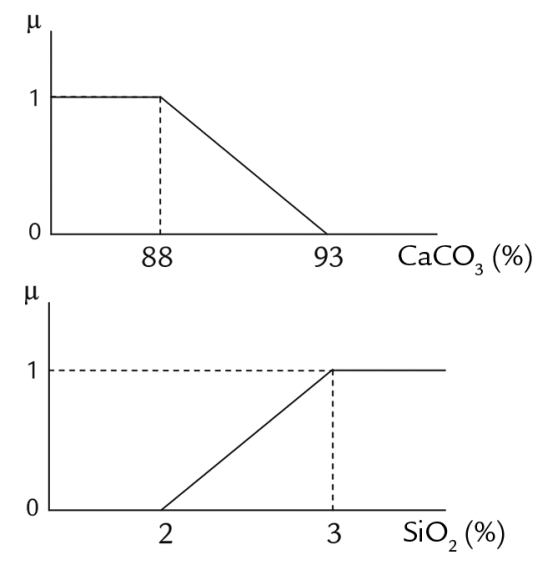

required by the plant (Eq. 11). In addition, it restricts the mining capacity in each mine site considering a possible

$$
\begin{gathered}
\sum_{i \in N} x_{i} \geq M_{C} \\
x_{i} \leq M_{i}, \forall i \in N
\end{gathered}
$$

exceed the prescribed upper bounds. For example, in the limestone case, the presence of Dolomite and Silica are unfavorable. These elements are assumed as penalty elements

$$
\begin{gathered}
\sum_{i \in N}\left(\tilde{q}_{k, i}-\tilde{Q}_{k, \max }\right) x_{i} \leq \tilde{0}, \forall k \in K \\
\sum_{i \in N}\left(-\tilde{g}_{i}+\tilde{G}_{\min }\right) x_{i} \leq \tilde{0}
\end{gathered}
$$

and are modeled using the Eq. (13). Constraint (14) ensures that the total amount of useful elements in the feed is always greater than the prescribed lower bounds.

in the mining complex is greater than the quantity required by the customers.

$$
\sum_{i \in N} \tilde{r}_{i} x_{i} \geq \tilde{P}_{C}
$$

are embedded into the model by Eq. (16).

$$
x_{i} \geq 0, \forall i \in N
$$

value, and the upper bound represents a risky and possible value. The FLP model (Eq. 10-16) is a nonlinear programming model and it could be easily converted into a linear programming model. Here, a solution procedure presented by Carlsson and Korhonen (1986) is applied to determine the optimum solution of the FLP model. limestone and dolomite beds are accompanied with cherty lenses. The limestone beds are Triassic light gray and regular bedded limestone. The limestone bed is located under a siliceous or cherty Limestone. This formation is covered by a dark color basaltic and some ferrugi-
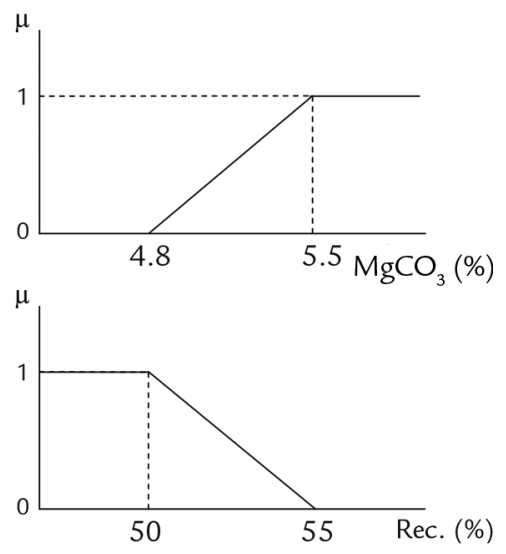

nous layers. The beds have a dip of 50 to 65 degrees. The thickness of limestone layers varies from 30 to 65 meters. Each mine is exploiting limestone from the outcrops of the beds.

These mines are producing limestone for a soda ash plant. The plant is
Figure 2

Membership function of fuzzy sets in Face\#1. 
producing sodium carbonate, which has many usages in industrial processes. The Quality Control (QC) office of the plant specifies the allowable quality of the feed. According to the QC requirements, the grade of $\mathrm{CaCO}_{3}$ should be more than $93.5 \%$, and the grade of $\mathrm{MgCO}_{3}$ and $\mathrm{SiO}_{2}$ in the feed should be less than $3.5 \%$ and $3 \%$ respectively.

According to the data gathered from the mine sites, the characteristics of limestone mined from each mine site are modeled as fuzzy numbers. The membership function of the fuzzy data for the Face\#1 is shown in Fig. 2. As the lower bound of each parameter represents a possible and implementable value, the minimum of the gathered data is thus selected as the lower bound. In case of positive parameters, such as ore grade (i.e. the percentage of $\mathrm{CaCO}_{3}$ ); the upper bound is selected to be the expected of the gathered data. However, in case of

Table 1 Characteristics of material.

Figure 3

Map of the mines and plant locations.

These data are fuzzified considering a deviation of $1 \%$ for the ore grade and $2 \%$ for the penalty elements from their

\section{Results and discussion}

The model (given in Eq. (3)-(5) and (7)-(9)) is solved with and without short sale restriction. The solution where no short sale restriction is applied is named 'Ideal-Solution' (IS). In addition, the solution where short sale restriction is applied negative parameters such as the grade of penalty elements (i.e. the percentage of $\mathrm{SiO}_{2}$ and $\mathrm{MgCO}_{3}$ ), the upper and lower bounds are selected vice versa (Table 1 ).

The other parameter that governs the scheduling of the mine is the possible mining capacities in each mine site. In this case, the lower bound of fuzzy representation indicates the current mining capacity in each mine site. These values are determined based on some local factors including pit geometry, and the thickness of limestone beds. The upper bound is an optimistic possible mining rate in each site. This value is determined based on the maximum mining rate that is reported from each mine site (Table 1).

The plant requires limestone with a size distribution of $5-12 \mathrm{~mm}$. The overall recovery of the material in the crushing unit depends on the mining operation itself and the mechanical char- acteristics of the limestone in each mine site. In this mine, following a blasting operation, the material is moved into a loading area by dozers and then loaded by excavators. The fragmentation of the limestone in each mine site is a function of blasting and dozing operations. The material is hauled to a crushing and blending unit from each mine site by trucks. The crushing unit is placed at a distance from each mine site (Fig. 3). According to the data and the experience of the mining crew, the overall recovery of the limestone mined from each mine face is also modeled using fuzzy numbers. The crushed material with the prescribed size distribution is fed into the soda ash plant. The current capacity of the plant is 1500 tons of crushed limestone each day (equals 45000 tons per month), and the nominal quality required by the plant is given in Table 1.

\begin{tabular}{c|c|c|c|c|c} 
Face & $\mathrm{CaCO}_{3}(\%)$ & $\mathrm{MgCO}_{3}$ & $\mathrm{SiO}_{2}(\%)$ & $\begin{array}{c}\text { Capacity } \\
(\mathrm{t} / \text { month })\end{array}$ & Recovery (\%) \\
\hline 1 & {$[88-93)$} & {$[5.5-4.8)$} & {$[3-2)$} & {$[9500-10000)$} & {$[50-55)$} \\
\hline 2 & {$[89.8-93)$} & {$[6.5-5.8)$} & {$[3.8-1.5)$} & {$[9500-10000)$} & {$[50-55)$} \\
\hline 3 & {$[93.5-96)$} & {$[3.8-2.8)$} & {$[3.5-1.4)$} & {$[32000-33000)$} & {$[55-62)$} \\
\hline 4 & {$[90-96)$} & {$[4.8-3)$} & {$[1.9-0.5)$} & {$[6500-8000)$} & {$[65-75)$} \\
\hline 5 & {$[89.7-95)$} & {$[5.8-4)$} & {$[3-2.2)$} & {$[40000-41000)$} & {$[60-70)$} \\
\hline Plant & {$[93.5,92.5)$} & {$[3.5-3.6)$} & {$[3-3.1)$} & 45000 & - \\
\hline
\end{tabular}

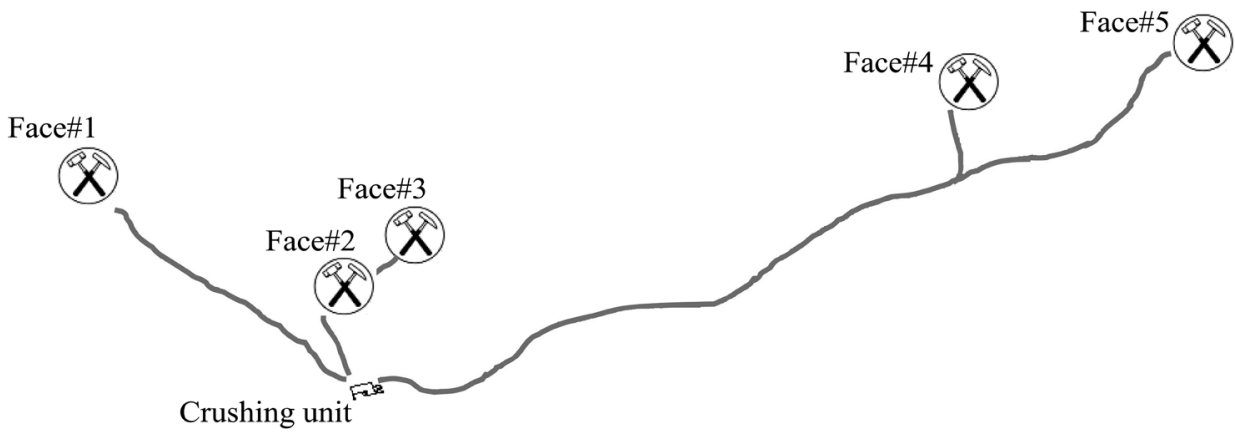

nominal qualification requirements. After fuzzification of the planning parameters, the model in Eq. 10-16 is applicable to de- termine the mining schedule. The model is programmed in "MatLab" and it is solved using the Simplex method. is named 'Relaxed-Solution' (RS) because in this case operational constraints are not considered. Finally, the solution where all of the restrictions are applied is named 'Constrained-Solution' (CS).All the solutions and the corresponding envelopes are shown in Fig. 4. In this figure, each mining face is depicted by a mean return and a risk level. As presented, Face\#3 has the lowest risk level, and Face\#4 has the highest mean return compared with other faces. The configurations of mining faces 
are determined using the gathered data and Monte Carlo simulation.

IS and RS results are the same for the cases where the mean-return is less than $65 \%$. As the required mean-return increases in Eq. (5), the optimal portfolio determined by the IS and RS becomes different. It should be noted that in the case of this paper, the results of IS are not logical because IS results are generated without short sale restriction. However, these results present an upper limit for production planning. According to IS and $\mathrm{RS}$ results, it is possible to minimize the production risks to $13 \%$. It means that, even with the strategy of over-design it is not possible to eliminate the risks. In fact, diversification of production risks is

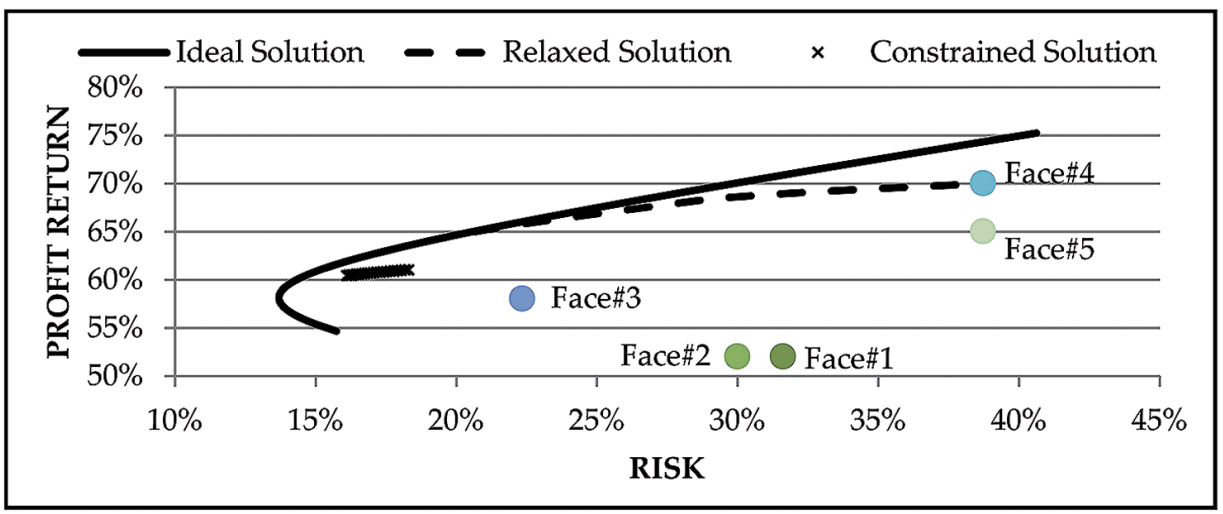

In order to determine CS, the model given in Eq. 10-16 is applied. The optimized mining plans are given in Table 2. CS determines the opti-

mum mining schedule with respect to given membership functions. As the membership value increases, the BFNs in the FLP model tend to their

\begin{tabular}{|c|c|c|c|c|c|c|}
\hline \multirow{2}{*}{$\begin{array}{l}\text { Member- } \\
\text { ship of } \\
\text { BFNs (\%) }\end{array}$} & \multicolumn{5}{|c|}{ Mining schedule } & \multirow{2}{*}{ Mining rate } \\
\hline & $x 1$ & $x 2$ & $x 3$ & $x 4$ & $x 5$ & \\
\hline 100 & 0 & 9500 & 32000 & 6500 & 30708 & 78708 \\
\hline 90 & 0 & 9550 & 32100 & 6650 & 29358 & 77658 \\
\hline 80 & 0 & 9600 & 32200 & 6800 & 28044 & 76644 \\
\hline 70 & 0 & 9650 & 32300 & 6950 & 26763 & 75663 \\
\hline 60 & 0 & 9700 & 32400 & 7100 & 25515 & 74715 \\
\hline 50 & 0 & 9750 & 32500 & 7250 & 24298 & 73798 \\
\hline 40 & 0 & 9800 & 32600 & 7400 & 23110 & 72910 \\
\hline 30 & 0 & 9850 & 32700 & 7550 & 21951 & 72051 \\
\hline 20 & 0 & 9900 & 32800 & 7700 & 20818 & 71218 \\
\hline 10 & 0 & 9950 & 32900 & 7850 & 19711 & 70411 \\
\hline 0 & 0 & 10000 & 33000 & 8000 & 18629 & 69629 \\
\hline
\end{tabular}

The CS results are all located below the IS and RS envelops, which means that the $\mathrm{CS}$ solutions are all feasible. According to the results, Face\#2, Face\#3 and Face\#4 are operating at their maximum nominal production rate in all the cases. When membership degree of BFNs decreases, then BFNs tend to their less risky values, and as a result, production rate at Face\#5 decreases. Face\#5 should produce 30708 and 18629 tons of limestone per month based on the presumed risk level. Considering the reserve characteristics in each mine site (Table 1), the reserve in Face\#1 is low in quality compared with the others, and according to the results, the mining effective in minimizing the un-systematic risks. Based on the results, the return of the portfolio is $57 \%$. According to the optimal portfolio, where the return is $57 \%$ and the risk is $13 \%$, the mining crew should extract material from all the faces. In this case, $17 \%, 17 \%, 37 \%, 15 \%$ and $14 \%$ of material should be mined from Face\#1 to Face\#5 respectively.

Figure 4

Efficient envelope of the mining schedule.

risky values. Then, the mining crew should produce more material in order to minimize the overall risk of the mining operation.
Table 2

The optimal CS

schedules (tons per month).

operation should be halted in this site. However, the mining costs in Face\#1 and Face\#2 are low compared with others and the model tends to exploit from these two sites to decrease the total mining costs. According to CS results, the lowest achievable risk level in the mine is $16 \%$ and the corresponding mean return is $60 \%$. 


\section{Conclusion}

In this paper, short-term production scheduling in the presence of uncertainty is optimized using two risk based mathematical models. Fuzzy linear programming is a useful tool for modeling and optimizing production plans in the presence of uncertainty. In addition, the problem of short-term production scheduling is investigated as a portfolio optimization problem. This approach suggests to the mine designer how the risk level of the production plan could be reduced. According to the models,

\section{References}

the minimum achievable risk level is $13 \%$. The amount of risk is caused by the un-systematic risks (or market risks) involved in the mining operation.

The presented models are capable of determining variable scenarios for the mining schedule. Therefore, the mine planner by considering the degree of preciseness of planning parameters is able to select the optimum mining schedule from among the presented scenarios. Introducing uncertainty into the production-planning model has increased the total amount of material that should be mined. This means that, the mining operation pays for the cost of uncertainty by excess production (overdesign). As shown in the case study, in the case of full uncertainty, the mine system should produce about 78708 tons of material in each month in order to satisfy the requirements of the plant. In the case of preciseness, however, the mining operation should be producing about 69629 tons of material, which is $12 \%$ less than the full uncertainty case.

ASAD, M. W. A.A heuristic approach to long-range production planning of cement quarry operations, Production Planning \& Control, v. 22, n. 4, p. 353-364, 2011.

AZIMI, Y., OSANLOO, M., ESFAHANIPOUR, A. An uncertainty based multi-criteria ranking system for open pit mining cut-off grade strategy selection, Resources Policy, v. 38, p. 212-223, 2013.

BADIOZAMANI, M.M., ASKARI-NASAB, H. Integration of reclamation and tailings management in oil sands surface mine planning, Environmental Modelling \& Software, v. 51, p. 45-58, 2014.

BENNINGA, S. Financial modeling. (3rd. ed.). London: Massachusetts Institute of Technology, 2008.

CACCETTA, L., HILL, S. P. An application of branch and cut to open pit mine scheduling, J. Global Optimization, v. 27, p. 349-365, 2003.

CARLSSON, C., KORHONEN, P. A parametric approach to fuzzy linear programming, Fuzzy Sets and Systems, v. 20, p. 17-30, 1986.

DAGDELEN, K. Open pit optimization - strategies for improving economics of mining projects through mine planning, In: DIMITRAKOPOULOS, R., (Ed.). Orebody modelling and stochastic mine planning, (2nd ed.). AusIMM, 2007. (Spectrum Series, n.14, p.145-148).

EIVAZY, H., ASKARI-NASAB, H. A mixed integer linear programming model for short-term open pit mine production scheduling, Mining Technology, v. 121, n. 2, p. 97-108, 2012.

FERNANDEZ, A., GOMEZ, S. Portfolio selection using neural networks. Comput. Oper. Res. v. 34, p. 1177-1191,2007.

FIORONI, M. M., BIANCHI, T. J., LUIZ, R. P. Concurrent simulation and optimization models for mining planning. In: WINTER SIMULATION CONFERENCE, Proceedings..., IEEE, p. 759-767, 2008.

GODOY, M., DIMITRAKOPOULOS, R. Managing risk and waste mining in long-term production scheduling of open-pit mines, SME Transactions, 316, p. 43-50, 2004.

HO, C. Evaluating the impact of operating environments on MRP system nervousness, International Journal of Production Research, v. 27, p. 1115-1135, 1989.

JUAREZ, G., DODDS, R., ECHEVERRIA, A., GUZMAN, J. I., RECABARREN, M., RONDA, J., VILA-ECHAGUE, E. Open pit strategic mine planning with automatic phase generation. In: DIMITRAKOPOULOS, R. (Ed.). OREBODY MODELLING AND STRATEGIC MINE PLANNING SYMPOSIUM. Proceedings... AusIMM, Perth (WA), 24-26, p. 147-153, Nov., 2014.

KING, B. Modelling open pit and underground production scheduling in concert.

In : DIMITRAKOPOULOS, R. (Ed.). In: OREBODY MODELLING AND STRATEGIC MINE PLANNING SYMPOSIUM. Proceedings... AusIMM, Perth (WA) 24-26, p. 369-373, Nov., 2014.

KUMRAL, M., DOWD, P. A. Short term mine production scheduling for industrial mineral using multi objective simulated annealing. In: APCOM, 30. Alaska: SME, p. 731-737. 
MARKOWITZ, H. Portfolio selection, J. Financ, v. 7, n.1, p. 77-91, 1952.

MARQUES, R. S., SOUZA, L. E., ALBARNAZ, L. D., NETO, R. O. Modeling and planning of bentonite clay mining: a case study at Bañado de Medina, Melo, Uruguay, REM: R. Esc. Minas, Ouro Preto, v. 66, n.4, p. 521-528, 2013.

MORLEY, C., SNOWDEN, V., DAY, D. Financial impact of resource / reserve uncertainty, The J. of the Southern African Institute of Mining and Metallurgy, v. 6, p. 293-302, 1999.

MULA, J., POLER, R., GARCIA-SABATER, J.P., LARIO F.C. Models for production planning under uncertainty: a review, Int. J. Production Economics, v. 103, p. 271-285, 2006.

NEWMAN, A. M., RUBIO, E., CARO, R., WEINTRAUB, A., EUREK, K. A review of operations research in mine planning, Interfaces, v. 40, n.3, p. 222-245, 2010.

OSANLOO, M., GHOLAMNEJAD, J., KARIMI, B. Long-term open pit mine production planning: a review of models and algorithms, Int. J. of Mining, Reclamation, and Environment, v. 22, n.1, p. 3-35, 2008.

SMITH, M. L. Optimizing short-term production schedules in surface mining: integrating mine modeling software with AMPL / CPLEX, Int. J. of mining, reclamation and environment, v. 12, p. 149-155, 1998.

SMITH, M.L., DIMITRAKOPOULOS, R. The influence of deposit uncertainty on mine production scheduling, Int. J. of mining, reclamation and environment, v. 13, p. 173-178, 1999.

SOUZA, M. J. F., COELHO, I. M., RIBAS, S., SANTOS, H. G., MERSCHMANN, L. H. C. A hybrid heuristic algorithm for the open-pit-mining operational planning problem. European J. of Operational Research. v. 207, n.2, p. 1041-1051, 2010.

Received: 7 June 2016 - Accepted: 26 October 2016. 